\title{
Major gene effects in systolic and diastolic blood pressure in families receiving a health examination in Taiwan Kuo-Liong Chien ${ }^{a, b}$, Chi-Yu Yang ${ }^{b}$ and Yuan-Teh Lee ${ }^{b}$
}

\begin{abstract}
Background Genetic factors play an important role in determining blood pressure values. Strong familial aggregation and estimated heritability values around $0.4-$ 0.6 were reported in a white population.
\end{abstract}

Objectives To investigate the genetic components and mode of inheritance of blood pressure in Taiwan.

Design A cross-sectional family study based on an adult population undergoing a health examination.

Setting and participants A total of 1313 adults and their spouses or first-degree relatives, or both, underwent a health examination in a tertiary university hospital from August 1998 to September 1999.

Main outcome measures Genetic analyses, including comingling analysis, familial correlation and complex segregation analysis, were used to detect the genetic components and the mode of inheritance of blood pressures.

Results In both systolic and diastolic blood pressure, the comingling analyses demonstrated that a more than onecomponent distribution provided the best fit for the data. The familial correlation coefficients showed significant parent-offspring and sibling correlation. Complex

\section{Introduction}

Hypertension is an important cardiovascular risk factor and well-controlled blood pressure can reduce cardiovascular morbidity and mortality. Many factors affect the control of blood pressure, such as obesity, dietary salt intake and physical inactivity. Besides environmental factors, genetic factors have a significant role in determining blood pressures.

Premature onset of hypertension among first-degree relatives increases the risk of developing hypertension up to 3.8-fold [1]. Reports of heritability estimates are available in western countries. In the French-Canadian population, genetic heritability estimates for blood pressure were relatively high in children (around 0.5$0.6)$ but much smaller in adults $(\sim 0.1-0.2)$ [2]. There was around $0.1-0.2$ heritability for blood pressure in Swedish families [3]. Friedlander et al. [4] demonstrated blood pressure heritability was around $0.2-0.3$ segregation analyses showed major gene effects in controlling systolic and diastolic blood pressure.

Conclusions There were significant genetic components in blood pressure among Taiwanese. Further investigation of genomic loci for the control of blood pressure is indicated. J Hypertens 21:73-79 $\odot 2003$ Lippincott Williams $\&$ Wilkins.

Journal of Hypertension 2003, 21:73-79

Keywords: blood pressure, familial correlation, comingling analysis, segregation analysis

${ }^{a}$ Graduate Institute of Preventive Medicine, School of Public Health, National Taiwan University and ${ }^{\mathrm{b}}$ Department of Internal Medicine, National Taiwan University Hospital, Taipei, Taiwan.

Sponsorship: The study was partly supported by the National Taiwan University Hospital (NTUH 90S1538, 1500-38-1538) and National Science Council in Taiwan (NSC 89-2314-B-002-403)

Correspondence and requests for reprints to Kuo-Liong Chien, MD, PhD, Graduate Institute of Preventive Medicine, School of Public Health, Room 213 19 Hsu Chow Road, Taipei, Taiwan 100.

Tel: +886223516478 ext 30; fax: +886223513750;

e-mail: klchien@ha.mc.ntu.edu.tw

Received 7 February 2002 Revised 2 October 2002

Accepted 4 October 2002

See editorial commentary page 19 in patients of a Jerusalem hyperlipidaemic clinic. In a rural agricultural population in India, the estimates of heritability of blood pressure reached as much as 0.3 [5].

The mode of inheritance as revealed by complex segregation analysis can provide evidence of whether there is a major gene effect for blood pressure, which is important for subsequent gene localization [6]. Even if some major susceptibility genes have already been identified, complex segregation analysis can help shed light on whether other genes exist [7]. To date, studies of complex segregation analysis on blood pressure have been conducted mainly in white and African-American families, and major gene effects were proven in several studies. In Israeli families recruited from the general population, systolic blood pressure was demonstrated to have major gene effects, with an allelic frequency of 0.18 [8]. In the study by Tiret et al. [9], only a major 
gene effect was demonstrated among healthy French families.

Why is it necessary to investigate the mode of inheritance of blood pressure in the general Chinese population? First, the mode of inheritance of blood pressure is still unclear, although significant heritability has been shown in Chinese children [10]. Secondly, blood pressure itself can be considered to be a good treatment target in clinical practice. Finally, results from a general population have a great impact on public health promotion and prevention strategies. This study, based on healthy adults who voluntarily received health screening in a tertiary hospital, was designed to explore the genetic components and modes of inheritance of systolic and diastolic blood pressure in Taiwanese.

\section{Materials and methods Study design}

This was a family-based study among the population who underwent a health examination in one tertiary hospital (the National Taiwan University Hospital). We recruited the study population on the basis that their spouse or first-degree relative received health screening at the same time. The health-screening programme was based on volunteer participants. Every participant gave signed informed consent, completed a questionnaire and received a physical examination when he/she came to the ward. Detailed medical history, smoking and drinking history were taken. Physical examination and 12-lead electrocardiogram were performed concurrently. Information about family history of coronary artery disease and stroke in first-degree relatives was collected by questionnaire. Individuals with significant cardiovascular morbidity, such as coronary heart disease and a history of stroke, were excluded from our study population.

\section{Blood pressure measurement}

Blood pressure was measured by mercury sphygmomanometer with the individual seated comfortably with the arms supported and positioned at the level of the heart. The measurements were taken on the arm after $10 \mathrm{~min}$ of rest. Two blood pressure readings were taken in each arm. The cuff bladder was inflated quickly, and then deflated by $2 \mathrm{mmHg}$ every $1 \mathrm{~s}$. If the readings taken varied by more than $10 \mathrm{mmHg}$, an additional reading was taken. The average values of blood pressure were taken for further analysis. The disappearance of Korotkoff phase $\mathrm{V}$ sound was recorded as diastolic pressure. The average of blood pressure from both arms was used in the final analysis. Neither smoking nor caffeine was permitted before the blood pressure measurement. Hypertension was defined as a systolic blood pressure more than $140 \mathrm{mmHg}$ or diastolic blood pressure more than $90 \mathrm{mmHg}$ or receipt of regular antihypertensive medication.

\section{Statistical analyses}

Systolic and diastolic blood pressures were described by their mean, variance, skewness and kurtosis. A linear regression model was used to obtain residual blood pressure values, after adjustment for age, sex and antihypertensive medication history, and the residual values plus sample means were used for further genetic analyses.

\section{Comingling analysis and familial correlation coefficients}

Comingling analysis of blood pressure was performed using the ADMIX program [11] to test whether the data were best described by one-, two-, or threecomponent distributions. The parameters for each component's mean, variance, and proportion were estimated by the maximum likelihood method. Hypothesis testing for nested models was carried out with the likelihood ratio test. The correlations of blood pressure between spouse, parent-offspring, and siblings were estimated by equal-weighted pairs, using the FCOR program in SAGE [12]. We tested the null hypothesis of correlation equal to 0 by $t$ statistics with degree of freedom by number minus 2 [13].

\section{Complex segregation analysis}

Segregation analyses of blood pressure values were conducted using regressive models as implemented in the REGC program in SAGE [12]. The methodology of segregation analyses is described in the Appendix.

We used residual blood pressure without logarithmic transformation for the segregation analysis, because normalizing transformation of a biologically skewed trait would decrease the power to detect a major gene effect when one exists [14]. Instead, we fitted the environmental effect. If such a model can be rejected, the major gene effect will not be due to skewness of blood pressure values [15].

\section{Results}

\section{Descriptive analysis}

From August 1998 to September 1999, a total of 4331 individuals completed the health examination. After exclusion of those individuals with a history of myocardial infarction $(n=7)$ and stroke $(n=10)$ in accordance with the primary prevention strategy in this study design, a total of 1313 (50.7\% women; mean age $54.7 \pm 11.5$ years, range $24-87$ years) were included into this family study on the basis that another family member was concurrently involved in the health examination. There were 530 spouse pairs, 76 parent-offspring pairs and 52 sibling pairs in the study population.

Table 1 shows some selected variables of the study population. The skewness and kurtosis of systolic and diastolic blood pressure were nearly 0 , indicating a 
Table 1 Basic demographic and atherosclerotic risk profiles in the study population

\begin{tabular}{lrccc}
\hline & \multicolumn{4}{c}{ Study population $(n=1313)$} \\
\cline { 2 - 5 } & Mean & SD & Skewness & Kurtosis \\
\hline Age (years) & 54.7 & 11.5 & -0.27 & 0.14 \\
SBP (mmHg) & 126.1 & 18.4 & 0.70 & 0.70 \\
DBP (mmHg) & 79.0 & 11.2 & 0.28 & 0.20 \\
\hline
\end{tabular}

SBP, systolic blood pressure; DBP, diastolic blood pressure; SD, standard deviation.

normal distribution of these traits. The prevalence of hypertension was $17.7 \%$ in this study population. Among the hypertensive group, $35 \%$ were receiving regular antihypertensive medication and the prevalence of electrocardiographic left ventricular hypertrophy was $14.9 \%$. Only $0.3 \%$ of the individuals had impaired renal function, defined as a serum creatinine concentration greater than $2.0 \mathrm{mg} / \mathrm{dl}$. After adjustment for age, sex and antihypertensive medication, the residual values were used for further analyses by adding sample means.

\section{Comingling analysis}

The three-component distribution model was the bestfitted model to explain the distribution of systolic blood pressure. The component means, variances, and proportions for this three-component distribution model were $(-0.435,0.671,3.496),(0.487,0.838,0.132)$, and $(62.9 \%$, $36.3 \%, 0.9 \%)$, respectively. The $\chi^{2}$ value for comparison between the three-component and two-component distributions was 10.24 [degrees of freedom $(\mathrm{df})=3$, $P=0.017]$, whereas that for comparison between the three-component and the four-component distribution was $0.70(\mathrm{df}=3, P=0.872)$. In the case of diastolic blood pressure, the best-fit model was the twocomponent distribution model; the corresponding values for means, variances and proportions were $(-0.296$, $0.875),(0.573,1.234)$ and $(74.7 \%, 25.3 \%)$, respectively. $\chi^{2}$ for comparison between the two-component and one-component distributions was $16.69(\mathrm{df}=3, P=$ 0.001), whereas that for comparison between the twocomponent and three-component distributions was 0.08 ( $\mathrm{df}=3, P=0.994)$. The distributions of the observed and expected values from component models were similar (Figs 1 and 2).

\section{Familial correlation coefficients}

For systolic blood pressure, there were low correlations between spouse pairs (0.083), greater correlations in parent-offspring pairs $(0.135)$, and the greatest among sibling pairs (0.309). The patterns of correlations in diastolic blood pressure were similar to those for systolic blood pressure, with the greatest in sibling pairs (0.464) (Table 2). The correlations were statistically significant in both spouse and sibling pairs for both blood pressures, but not significant in parent-offspring pairs.
Fig. 1

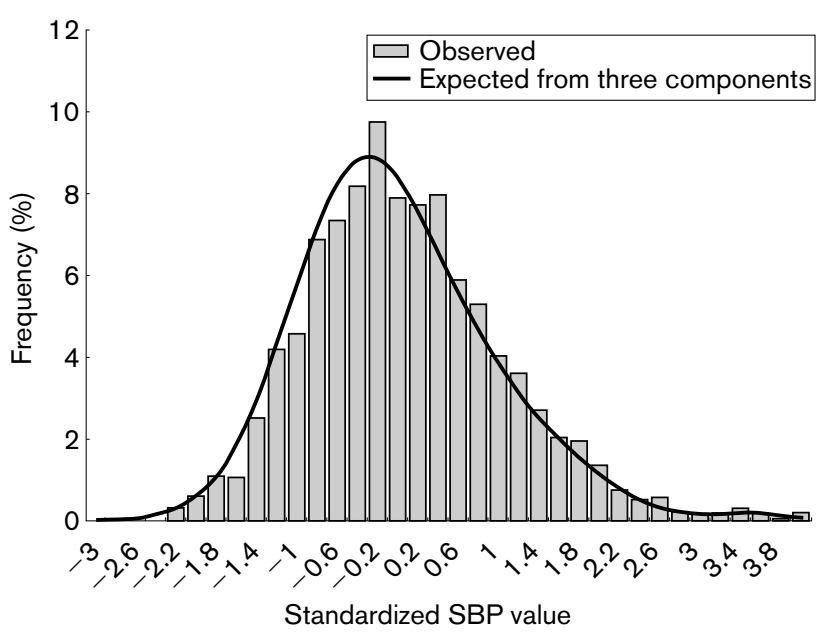

Distribution of comingling analysis for systolic blood pressures (SBP), after adjustment for age and sex effects.

Fig. 2

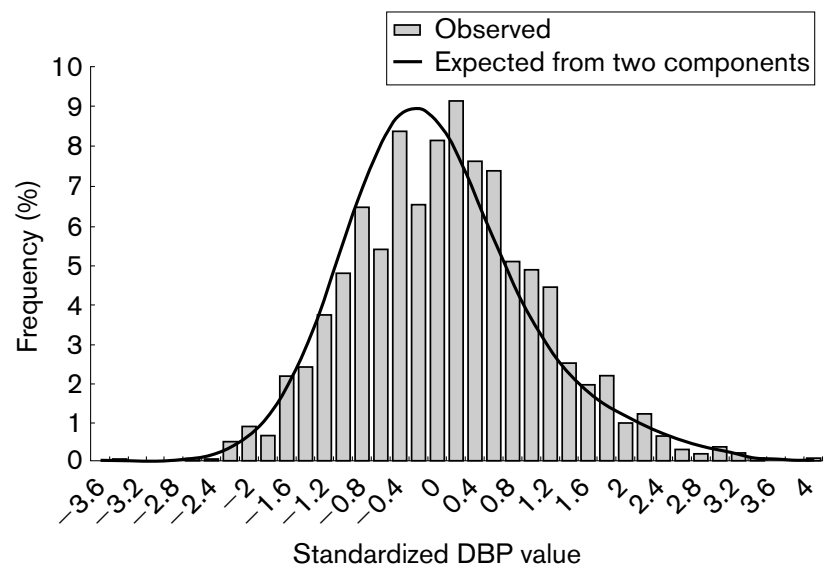

Distribution of comingling analysis for diastolic blood pressures (DBP), after adjustment for age and sex effects.

\section{Complex segregation analysis}

Initially, we tested whether the two-parameter familial correlation was compatible with the four-parameter model in the family data. The $\chi^{2}$ values were 1.38 $(\mathrm{df}=2, P=0.502)$ for systolic blood pressure and 5.07 $(\mathrm{df}=2, P=0.079)$ for diastolic blood pressure, indicating that the two-parameter familial correlation model was not significantly different from the four-parameter model. For reasons of economy, we performed the following segregation analyses by the two-parameter familial correlation model.

For systolic blood pressure, we compared several models against the general model, including the sporadic, 


\begin{tabular}{|c|c|c|c|c|c|c|c|}
\hline \multirow[b]{2}{*}{ Pair } & \multirow[b]{2}{*}{ No. } & \multicolumn{3}{|c|}{ Systolic blood pressure } & \multicolumn{3}{|c|}{ Diastolic blood pressure } \\
\hline & & $\begin{array}{l}\text { Estimated } \\
\text { correlation }\end{array}$ & $t$ value & $P$ value & $\begin{array}{l}\text { Estimated } \\
\text { correlation }\end{array}$ & $t$ value & $P$ value \\
\hline Spouse & 530 & 0.083 & 1.91 & 0.056 & 0.175 & 4.08 & 0.000 \\
\hline Parent-offspring & 76 & 0.135 & 1.17 & 0.245 & 0.189 & 1.66 & 0.102 \\
\hline Sibling & 52 & 0.309 & 2.30 & 0.026 & 0.464 & 3.70 & 0.001 \\
\hline
\end{tabular}

pure polygenes, pure major genes, mixed environmental, mixed major gene effects, and dominant and recessive major gene effect models (Table 3 ). The $P$ values were less than 0.0001 in several models, and borderline significant in the mixed major gene and pure major gene models (both $P=0.01$ ). If we choose the best model by Akaike information criteria (AIC) [16], the mixed major gene model was better than the other models $(\mathrm{AIC}=11036.52)$. Therefore we concluded that there exists one codominant major gene effect for the control of systolic blood pressure, and that the frequency of this allele for high systolic blood pressure is 0.139 ; the three mean values were $175.6,141.7$ and $119.7 \mathrm{mmHg}$. The estimated spouse correlation was 0.116 and the parent-offspring and sibling correlation was 0.169 , with estimated heritability of 0.18 .

For diastolic blood pressure, comparing several models with the general model, we found that there were several models, including mixed major gene, pure major gene and environmental, with $P$ values greater than 0.05 (Table 4). The mixed major gene model has the smallest AIC value (9910.21), so we concluded that the mixed major gene model is the model of best-fit for diastolic blood pressure. The allelic frequency of the allele controlling high diastolic blood pressure was 0.246 , and three mean values were 97.7, 82.5 and $74.7 \mathrm{mmHg}$. The correlation coefficients in spouse and siblings were 0.271 and 0.241 , respectively, with an estimated heritability up to 0.33 .

\section{Discussion}

This study clearly demonstrated that there were significant familial aggregation and comingling components in systolic and diastolic blood pressure, and major gene effects were clearly demonstrated in the adult Taiwanese population.

The study population were from adult volunteers receiving health screening and therefore with a low prevalence of risk factors or end-organ damage. The results of this study are thus particularly relevant for a population at low risk for atherosclerosis. Our study demonstrated that a more than one-component distribution explained blood pressure well. The finding of multiple distributions is compatible with a major gene hypothesis; however, comingling may also arise through other causes. Thus segregation analysis was used to determine whether these major effects segregated in families according to Mendelian expectations. Our studies demonstrated that the genetic components are attributable to major genes effects, not only to the polygenes background. The results were compatible with those from previous population-based studies [8,17-19].

The estimated allelic frequencies controlling systolic and diastolic blood pressure were different in this study (0.139 compared with 0.244 , respectively). Also, the estimated correlations were different in the final two models. The reasons for these observations may be as follows. First, different genetic components are responsible for systolic and diastolic blood pressure. Under conditions of exercise and stress, only diastolic blood pressure, not systolic blood pressure, can be proved to have the major gene effects [19]. Second, the estimated parameters of both models were affected differentially by environmental and lifestyle risk factors; for example, physical inactivity, obesity and salt intake have effects on blood pressure, and were not in the analyses. Third, there are gene-gene interactions and gene-environmental interactions that cannot be resolved by segregation analyses. Finally, there is probably more than one gene controlling blood pressure. Fortunately, even if segregation analysis is assumed to be a one-locus model, the power of detecting a 'major gene in multiple loci' model is still significantly high $[20,21]$.

The frequency estimates for the allele controlling high blood pressure and the absolute blood pressure difference (displacement) in two- or three-component models were different in the results from the comingling and the segregation analyses. A possible explanation is that different parametric assumptions were made in both analyses. We can nevertheless use the estimated parameters from comingling components as initial values for segregation analysis [22].

Also, our study results showed significant spouse correlations in blood pressure, indicating the involvement of common shared household environmental factors in controlling blood pressure. Common household factors, 


\begin{tabular}{|c|c|c|c|c|c|c|c|c|c|c|c|c|c|c|c|c|}
\hline & \multicolumn{16}{|c|}{ Model } \\
\hline & \multicolumn{2}{|c|}{ Sporadic } & \multicolumn{2}{|c|}{ Polygenes } & \multicolumn{2}{|c|}{ Environmental } & \multicolumn{2}{|c|}{ Mixed Mendel } & \multicolumn{2}{|c|}{ Pure Mendel } & \multicolumn{2}{|c|}{ Dominant } & \multicolumn{2}{|c|}{ Recessive } & \multicolumn{2}{|c|}{ General } \\
\hline & Estimate & SE & Estimate & SE & Estimate & SE & Estimate & SE & Estimate & SE & Estimate & SE & Estimate & SE & Estimate & SE \\
\hline$q_{A}$ & [1] & & [1] & & 0.284 & 0.044 & 0.139 & 0.029 & 0.141 & 0.032 & 0.037 & 0.011 & 0.282 & 0.039 & 0.155 & 0.024 \\
\hline$\tau_{\mathrm{AA}}$ & - & & - & & $=q_{A}$ & & [1] & & [1] & & [1] & & [1] & & 0.000 & 0.000 \\
\hline$\tau_{A B}$ & - & & - & & $=q_{A}$ & & {$[0.5]$} & & {$[0.5]$} & & {$[0.5]$} & & {$[0.5]$} & & 0.000 & 0.000 \\
\hline$\tau_{\mathrm{BB}}$ & - & & - & & $=\mathrm{q}_{\mathrm{A}}$ & & [0] & & [0] & & [0] & & [0] & & 0.248 & 0.065 \\
\hline$\mu_{\mathrm{AA}}$ & 126.1 & 0.5 & 126.0 & 0.5 & 157.7 & 3.7 & 175.6 & 5.1 & 174.9 & 5.3 & 159.2 & 3.6 & 158.2 & 3.4 & 173.4 & 4.2 \\
\hline$\mu_{A B}$ & $=\mu_{\mathrm{AA}}$ & & $=\mu_{\mathrm{AA}}$ & & 123.3 & 4.4 & 141.7 & 2.9 & 141.5 & 3.0 & 159.2 & 3.6 & 123.3 & 0.7 & 140.8 & 2.1 \\
\hline$\mu_{\mathrm{BB}}$ & $=\mu_{\mathrm{AA}}$ & & $=\mu_{\mathrm{AA}}$ & & 123.3 & 3.5 & 119.7 & 1.0 & 119.7 & 1.0 & 123.5 & 0.7 & 123.3 & 0.7 & 118.9 & 0.9 \\
\hline$\sigma^{2}$ & 287.2 & 11.2 & 287.4 & 11.3 & 199.2 & 13.7 & 150.2 & 12.4 & 150.9 & 12.5 & 201.7 & 12.7 & 198.2 & 12.7 & 139.7 & 10.8 \\
\hline$\rho_{\mathrm{MF}}$ & [0] & & 0.084 & 0.043 & 0.109 & 0.055 & 0.116 & 0.074 & 0.117 & 0.074 & 0.111 & 0.054 & 0.110 & 0.055 & 0.113 & 0.079 \\
\hline$\rho_{\mathrm{MO}}=\rho_{\mathrm{FO}}=\rho_{\mathrm{SS}}$ & [0] & & 0.229 & 0.092 & 0.235 & 0.105 & 0.169 & 0.116 & [0] & & 0.186 & 0.102 & 0.209 & 0.106 & 0.496 & 0.128 \\
\hline$n$ & 2 & & 4 & & 7 & & 7 & & 6 & & 6 & & 6 & & 10 & \\
\hline$-2 \ln (\mathrm{L})$ & 11115.28 & & 11106.03 & & 11033.01 & & 11022.52 & & 11024.54 & & 11031.46 & & 11029.78 & & 11011.00 & \\
\hline$\chi^{2}$ & 104.28 & & 95.03 & & 22.01 & & 11.52 & & 13.54 & & 20.46 & & 18.78 & & & \\
\hline AIC & 11119.28 & & 11114.03 & & 11047.01 & & 11036.52 & & 11036.54 & & 11043.46 & & 11041.78 & & 11031.00 & \\
\hline$P$ & 0.000 & & 0.000 & & 0.000 & & 0.01 & & 0.01 & & 0.000 & & 0.001 & & Baseline & \\
\hline
\end{tabular}

Numbers in square brackets represent fixed value under the model. $q_{A}$, gene frequency; $\tau_{A A} \tau_{A B}, \tau_{B B}$, transmission probabilities; $\mu_{A A}, \mu_{A B}$, $\mu_{B B}$, genotype means; $\sigma^{2}$, variance; $\rho_{M F}, \rho_{M O}, \rho_{F O}$, $\rho_{S S}$, correlation coefficients among spouse, mother-offspring, father-offspring and sibling pairs; $n$, number of parameters; In $(L)$, logarithm of likelihood; AIC, Akaike information criteria; $P$, significance level compared with the unrestricted general model.

Table 4 Parameter estimates from segregation analysis of residual diastolic blood pressure values: class $D$ regressive models

\begin{tabular}{|c|c|c|c|c|c|c|c|c|c|c|c|c|c|c|c|c|}
\hline & \multicolumn{16}{|c|}{ Model } \\
\hline & \multicolumn{2}{|c|}{ Sporadic } & \multicolumn{2}{|c|}{ Polygenes } & \multicolumn{2}{|c|}{ Environmental } & \multicolumn{2}{|c|}{ Mixed Mendel } & \multicolumn{2}{|c|}{ Pure Mendel } & \multicolumn{2}{|c|}{ Dominant } & \multicolumn{2}{|c|}{ Recessive } & \multicolumn{2}{|c|}{ General } \\
\hline & Estimate & SE & Estimate & SE & Estimate & SE & Estimate & SE & Estimate & SE & Estimate & SE & Estimate & SE & Estimate & SE \\
\hline$q_{A}$ & [1] & & [1] & & 0.226 & 0.122 & 0.246 & 0.169 & 0.244 & 0.078 & 0.043 & 0.023 & 0.303 & 0.071 & 0.286 & 0.038 \\
\hline$\tau_{A A}$ & - & & - & & $=q_{A}$ & & [1] & & [1] & & [1] & & [1] & & 1.000 & 0.000 \\
\hline$\tau_{A B}$ & - & & - & & $=\mathrm{q}_{\mathrm{A}}$ & & {$[0.5]$} & & {$[0.5]$} & & {$[0.5]$} & & {$[0.5]$} & & 0.364 & 0.153 \\
\hline$\tau_{\mathrm{BB}}$ & - & & - & & $=\mathrm{q}_{\mathrm{A}}$ & & [0] & & [0] & & [0] & & [0] & & 0.000 & 0.000 \\
\hline$\mu_{\mathrm{AA}}$ & 79.0 & 0.3 & 79.0 & 0.3 & 98.7 & 5.3 & 97.7 & 8.1 & 98.2 & 3.4 & 95.3 & 3.1 & 95.0 & 2.8 & 97.3 & 2.2 \\
\hline$\mu_{\mathrm{AB}}$ & $=\mu_{\mathrm{AA}}$ & & $=\mu_{\mathrm{AA}}$ & & 84.3 & 4.7 & 82.5 & 8.5 & 83.4 & 2.5 & 95.3 & 3.1 & 77.4 & 0.6 & 72.2 & 1.6 \\
\hline$\mu_{\mathrm{BB}}$ & $=\mu_{\mathrm{AA}}$ & & $=\mu_{\mathrm{AA}}$ & & 74.2 & 1.6 & 74.7 & 1.5 & 74.2 & 1.3 & 77.5 & 0.7 & 77.4 & 0.6 & 81.5 & 1.1 \\
\hline$\sigma^{2}$ & 117.4 & 4.6 & 117.5 & 4.7 & 74.5 & 8.7 & 81.4 & 20.4 & 75.3 & 9.4 & 93.1 & 7.0 & 91.9 & 6.8 & 69.6 & 12.6 \\
\hline$\rho_{\mathrm{MF}}$ & [0] & & 0.177 & 0.042 & 0.303 & 0.073 & 0.271 & 0.097 & 0.294 & 0.073 & 0.235 & 0.054 & 0.238 & 0.054 & 0.323 & 0.090 \\
\hline$\rho_{\mathrm{MO}}=\rho_{\mathrm{FO}}=\rho_{\mathrm{SS}}$ & [0] & & 0.308 & 0.080 & 0.458 & 0.130 & 0.241 & 0.108 & [0] & & 0.000 & 0.000 & 0.000 & 0.000 & 0.337 & 0.115 \\
\hline & 2 & & 4 & & 7 & & 7 & & 6 & & 6 & & 6 & & 10 & \\
\hline$-2 \ln (\mathrm{L})$ & 9945.47 & & 9917.11 & & 9896.39 & & 9896.21 & & 9900.87 & & 9904.28 & & 9904.30 & & 9891.83 & \\
\hline$\chi^{2}$ & 53.64 & & 25.28 & & 4.56 & & 4.38 & & 9.04 & & 12.45 & & 12.47 & & & \\
\hline AIC & 9949.47 & & 9925.11 & & 9910.39 & & 9910.21 & & 9912.87 & & 9916.28 & & 9916.3 & & 9911.83 & \\
\hline$P$ & 0.000 & & 0.000 & & 0.207 & & 0.223 & & 0.060 & & 0.014 & & 0.014 & & Baseline & \\
\hline
\end{tabular}

Numbers in square brackets represent fixed value under the model. $q_{\mathrm{A}}$, gene frequency; $\tau_{\mathrm{AA}}, \tau_{\mathrm{AB}}, \tau_{\mathrm{BB}}$, transmission probabilities; $\mu_{\mathrm{AA}}, \mu_{\mathrm{AB}}, \mu_{\mathrm{BB}}$, genotype means; $\sigma^{2}$, variance; $\rho_{\mathrm{MF}}, \rho_{\mathrm{MO}}, \rho_{\mathrm{FO}}, \rho_{\mathrm{SS}}$, correlation coefficients among spouse, mothe-offspring, father-offspring and sibling pairs; $n$, number of parameters; In $(\mathrm{L})$, logarithm of likelihood; AIC, Akaike information criteria; $P$, significance level compared with the unrestricted general model. 
such as cultural influences, have important roles in the pathogenesis of hypertension [23-25]. Family-based intervention programmes, such as dietary modification and promotion of exercise, are important and feasible for the prevention of hypertension [26,27].

Although there are many candidate genes and genomewide linkage reports for blood pressure, the identifying characteristics of the individual genes contributing to blood pressure and the occurrence of hypertension in the population at large remain poorly defined [28,29]. Moreover, the quantitative estimation of heritability values varies according to inter-generational difference or age effects, with relatively low genetic heritability in the adult population [3]. Population heterogeneity and phenocopy are also difficult problems to resolve. Nevertheless, for this study based on a population sample receiving health screening, we are optimistic that the results can be extrapolated to the general adult Taiwanese population and provide a primary prevention strategy for blood pressure control.

Sing et al. [30] proposed the genetic model as an approach to the study of genetic factors in complex traits. The bottom-up approach is to use known genotype markers to assess the phenotypes, and the topdown approach is to study phenotype by genetic epidemiological methods. Because genotyping work very much depends on bench facilities, clinicians always collect the traits and possible intermediate phenotypes first, and use quantitative genetics to explore possible familial aggregation and estimated heritability and genetic components. In this study, we clearly demonstrated genetic components in blood pressure; identification of further genes can now be proposed.

The limitation of this study was twofold. First, because our ascertainment strategy was based on adults undergoing a health examination, the sample was composed of more spouse pairs than sibling pairs $(530$ and 52, respectively). Although there was a disproportionately low number of sibling pairs, the coefficients among sibling pairs nevertheless attained significance. This is possibly because of significant genetic components in blood pressure traits. Secondly, hypertension is a complex trait and several genetic and environmental factors are involved in the pathogenesis. Although segregation analysis cannot identify the genetic locus, its contribution lies in the detection of major gene components in the specified trait and in providing parameter estimates for further linkage analyses. Furthermore, the analysis remained powerful in the two-locus model [20].

In conclusion, significant familial aggregation and major gene effects were demonstrated among the adult participants who received health screening in Taiwan.

\section{Acknowledgements}

The authors are most grateful for the help and cooperation of staff in the health examination ward in National Taiwan University Hospital.

\section{References}

1 Williams RR, Hunt SC, Hasstedt SJ, Hopkins PN, Wu LL, Berry TD, et al. Are there interactions and relations between genetic and environmental factors predisposing to high blood pressure? Hypertension 1991; 18:129-I37.

2 Perusse L, Rice T, Bouchard C, Vogler GP, Rao DC. Cardiovascular risk factors in a French-Canadian population: resolution of genetic and familial environmental effects on blood pressure by using extensive information on environmental correlates. Am J Hum Genet 1989; 45:240-251.

3 Faire UD, Iselius L, Lundman T. Biological and cultural determinants of blood pressure. Hypertension 1982; 4:725-728.

4 Friedlander Y, Kark JD, Stein Y. Biological and environmental sources of familial aggregation of blood pressure: the Jerusalem Lipid Research Clinic. Int J Epidemiol 1988; 17:70-76.

5 Majumder PP, Bhattacharya SK, Mukerrjee BN, Rao DC. Genetic epidemiologic study of blood pressure in a sedentary rural agricultural population of West Bengal, India. Am J Phys Anthrop 1990; 81: $563-572$.

6 Jarvik GP. Complex segregation analyses: uses and limitations. Am J Hum Genet 1998; 63:942-946.

7 Cui J, Antoniou AC, Dite GS, Southey MC, Venter DJ, Easton DF, et al. After BRCA1 and BRCA2 what is next? Multifactorial segregation analyses of three-generation, population-based Australian families affected by female breast cancer. Am J Hum Genet 2001; 68:420-431.

8 Cheng LS, Livshits G, Carmelli D, Wahrendorf J, Brunner D. Segregation analysis reveals a major gene effect controlling systolic blood pressure and $\mathrm{BMI}$ in an Israeli population. Hum Biol 1998; 70:59-75.

9 Tiret L, Rigat B, Visvikis S, Breda C, Corvol P, Cambien F, et al. Evidence, from combined segregation and linkage analysis, that a variant of the angiotensin l-converting enzyme (ACE) gene controls plasma ACE levels. Am J Hum Genet 1992; 51:197-205.

10 Wang Z, Quyang Z, Wang D, Tang X. Heritability of blood pressure in 7to 12 -year-old Chinese twins, with special reference to body size effects. Gene Epidemiol 1990; 7:447-452.

11 Cloninger CR, von Knorring L, Oreland L. Pentametric distribution of platelet monoamine oxidase activity. Psychiatr Res 1985; 15:133-143.

12 S.A.G.E. Statistical analysis for genetic epidemiology, Release 3.11997. Computer program package available from the Department of Epidemiology and Biostatistics, Rammelkamp Center for Education and Research, MetroHelath Campus, Case Western Reserve University, Cleveland, Ohio, USA.

13 Snedecor GW, Cochran WG. Statistical methods, 7th ed. Ames, lowa, USA: The lowa State University Press; 1980. pp. 78-81.

14 MacLean CJ, Morton NE, Lew R. Analysis of family resemblance. IV. Operational characteristics of segregation analysis. Am J Hum Genet 1975; 27:365-384.

15 Demenais F, Lathrop M, Lalouel JM. Robustness and power of the unified model in the analysis of quantitative measurements. Am J Hum Genet 1986; 38:228-234.

16 Akaike $\mathrm{H}$. A new look at the statistical model identification. IEEE Trans Automatic Control 1974; 19:716-723.

17 Perusse L, Moll PP, Sing CF. Evidence that a single gene with genderand age-dependent effects influences systolic blood pressure determination in a population-based sample. Am J Hum Genet 1991; 49:94-105.

18 Weissbecker KA. Segregation analysis of diastolic blood pressure in a large pedigree. Genet Epidemiol 1993; 10:659-664.

19 Cheng LSC, Carmelli D, Hunt SC, Williams RR. Segregation analysis of cardiovascular reactivity to laboratory stressors. Genet Epidemiol 1997; 14:35-49.

20 Dizier MH, Bonaiti-Pellie C, Clerget-Darpoux F. Conclusions of segregation analysis for family data generated under two-locus models. Am $J$ Hum Genet 1993; 53:1338-1346.

21 Go RC, Elston RC, Kaplan EB. Efficiency and robustness of pedigree segregation analysis. Am J Hum Genet 1978; 30:28-37.

22 Kwon JM, Boehnke M, Burns TL, Moll PP. Comingling and segregation analyses: comparison of results from a simulation study of a quantitative trait. Genet Epidemiol 1990; 7:57-68.

23 Williams RR, Rao DC, Ellison RC, Arnett DK, Heiss G, Oberman A, et al. NHLBI family blood pressure program: methodology and recruitment in the HyperGEN network. Hypertension genetic epidemiology network. Ann Epidemiol 2000; 10:389-400. 
24 Rice T, Province M, Perusse L, Bouchard C, Rao DC. Cross-trait familial resemblance for body fat and blood pressure: familial correlations in the Quebec Family Study. Am J Hum Genet 1994; 55:1019-1029.

25 Ward R. familial aggregation and genetic epidemiology of blood pressure. In: Laragh JH, Brenner BM (editors): Hypertension: pathophysiology, diagnosis and management. New York: Raven Press; 1990. pp. 81-100.

26 Knutsen SF, Knutsen R. The Tromso Survey: the Family Intervention study - the effect of intervention on some coronary risk factors and dietary habits, a 6-year follow-up. Prev Med 1991; 20:197-212.

27 Perry CL, Griffin G, Murray DM. Assessing needs for youth health promotion. Prev Med 1985; 14:379-393.

28 Williams RR, Hunt SC, Hasstedt SJ, Hopkins PN, Wu LL, Berry TD, et al. Genetics of hypertension: what we know and don't know. Clin Exp Hypertens [A] 1990; 12:865-876.

29 Williams RR, Hunt SC, Hopkins PN, Hasstedt SJ, Wu LL, Lalouel JM. Tabulations and expectations regarding the genetics of human hypertension. Kidney Int Supp/ 1994; 44:S57-S64.

30 Sing CF, Boerwinkle E, Moll PP, Templeton AR. Characterization of genes affecting quantitative traits in humans. In: Weir BS, Eisen EJ, Goodman MM, Namkoong G (editors): Proceedings of the second international conference on quantitative genetics. Sunderland, Massachusettes: Sinauer Associates Inc.; 1988. pp. 250-269.

31 Cannings C, Thompson EA, Skolnick MH. Probability function on complex pedigrees. Adv Appl Prob 1978; 10:26-61.

32 Demenais FM, Bonney GE. Equivalence of the mixed and regressive models for genetic analysis. I. Continuous traits. Genet Epidemiol 1989; 6:597-617.

\section{Appendix}

\section{Methodology of complex segregation analysis}

These models assume that variation in blood pressure among family members is the result of a major gene effect, with the residual variation reflecting both familial correlations and individual variation. The presence of a major gene is assessed by assuming two factors or alleles ( $\mathrm{A}$ and $\mathrm{B}$ ) at a single locus, resulting in three 'ousiotypes' (AA, AB, BB) in individuals [31]. The mean of blood pressure for each ousiotype is denoted $\mu_{\mathrm{AA}}, \mu_{\mathrm{AB}}$ and $\mu_{\mathrm{BB}}$, with one common variance of $\sigma^{2}$. The frequencies of alleles $\mathrm{A}$ and $\mathrm{B}$ are denoted $\mathrm{q}_{\mathrm{A}}$ and $\left(1-q_{A}\right)$, respectively. The distribution of types in the population is assumed to be in Hardy-Weinberg equilibrium. Individuals of each type are assumed to transmit allele A to their offspring with transmission probabilities $\tau_{\mathrm{AA}}, \tau_{\mathrm{AB}}$ and $\tau_{\mathrm{BB}}$, respectively. Residual familial resemblance not explained by this major locus is modelled by familial correlations. The correlations between spouses, parent and offspring, mother and offspring, father and offspring, and between siblings, are denoted $\rho_{\mathrm{MF}}, \rho_{\mathrm{PO}}, \rho_{\mathrm{MO}}, \rho_{\mathrm{FO}}$ and $\rho_{\mathrm{SS}}$, respectively. For this study, we adopted class $\mathrm{D}$ regressive models, in which residual sib-sib correlations are equal among all sibs of common parentage and can be due to any cause. There were greater numbers of spouse pairs than parent-offspring pairs in this study population, so initially we tested whether familial correlation numbers could be reduced from four $\left(\rho_{\mathrm{MF}}, \rho_{\mathrm{MO}}, \rho_{\mathrm{FO}}\right.$ and $\left.\rho_{\mathrm{SS}}\right)$ to two $\left(\rho_{\mathrm{MF}}, \rho_{\mathrm{PO}}=\rho_{\mathrm{MO}}=\rho_{\mathrm{FO}}=\rho_{\mathrm{SS}}\right)$. If $\rho_{\mathrm{PO}}$ is held equal to $\rho_{S S}$, these models have been shown to be mathematically and numerically equivalent to the conventional mixed model of inheritance in nuclear families [14]. The heritability can be estimated as $2 \rho_{\mathrm{SS}}\left(\sigma^{2} / \sigma^{2} \mathrm{~T}\right)$, where $\sigma^{2} \mathrm{~T}$ is the total variance and $\sigma^{2}$ is the variance conditional on the major ousiotype [32].
The analyses started with fitting a general model, in which all parameters were allowed to be estimated. Then we compared the general model with various submodels in which certain parameters were restricted to specific values. Under a Mendelian model, the transmission probabilities - that is $\tau_{\mathrm{AA}}, \tau_{\mathrm{AB}}$ and $\tau_{\mathrm{BB}}-$ were held equal to Mendelian expectations of $1,0.5$ and 0 . A non-transmitted environmental effect model predicts that the probability that an individual has one ousiotype or another is independent of both the person's generation and the ousiotypes of his/her parents. For the environmental model in this study, each of the transmission probabilities is taken to be equal to the factor frequency: $\tau_{\mathrm{AA}}=\tau_{\mathrm{AB}}=\tau_{\mathrm{BB}}=\mathrm{q}_{\mathrm{A}}$. Both the Mendelian and environmental models can allow for residual familial correlations. A pure polygenic model assumes no major gene effect, so gene frequency and transmission probabilities are all fixed as 1 . The fit of hierarchical models is compared with the likelihood ratio test, calculated as -2 of the difference between the $\log _{n}$ likelihood of the models being compared. The likelihood ratio value follows a $\chi^{2}$ distribution, with degrees of freedom equal to the difference between the models in the number of parameters estimated. Among nonhierarchical models, the most parsimonious model is that with the lowest values of Akaike's information criterion $\left(\mathrm{AIC}=-2 \log _{\mathrm{n}}\right.$ likelihood +2 [number of estimated parameters]) [16]. 